\title{
STUDI LITERATURE KESULITAN SISWA SMP/MTS DIPONEGORO WULUHAN DALAM PEMBELAJARAN MATA PELAJARAN BAHASA INGGRIS
}

\author{
Lamatsil Imroatus Sholehah \\ Program Studi Pendidikan IPA Jurusan Pendidikan MIPA \\ Fakultas Keguruan Dan Ilmu Pendidikan Universitas Jember \\ Jl. Kalimantan 37, Jember 628121
}

\begin{abstract}
Learning difficulty is a condition where students experience learning disruptions as they should, both from internal and external factors. This results in students not being able to develop according to their capacity. From this research can be put forward the formulation of the problem, namely, the types of learning difficulties experienced by junior high school / junior high school students in North Sumatra, what factors that make students difficult to learn in English, and how can efforts solve the problem of student learning difficulties. The purpose of this study was to determine the types of difficulties in understanding completing the material in English subjects, the factors that influence students in understanding completing the material in English subjects and problem solving efforts. The method used in this study is to use qualitative methods. Data collection techniques used were literature studies and interviews with each student were different classes. The results of this study are that there are still some students who still have difficulty in understanding completing the material in English subjects from the aspects of listening, reading, structure, and writing, and which are the factors causing students to experience learning difficulties, namely from cognitive factors (ability to memorize, the ability to master the material and the wrong learning habits, and what efforts will be used by educators using teaching repairs.
\end{abstract}

Keywords: learning difficulties, students, English.

\section{PENDAHULUAN}

Menurut undang-undang sistem pendidikan nasional No.20 tahun 2003 adalah usaha sadar dan terencana untuk mewujudkan dan proses pembelajaran agar peserta didik dapat secara aktif mengembangkan potensi dirinya sendiri agar memiliki kekuatan spiritual, pengendalian diri diri, kepribadian,kecerdasan, akhlak mulia, serta ketrampilan yang diperlukan oleh dirinya dan masyarakat.

Pendidikan adalah proses atau kegiatan pembelajaran peserta didik untuk mengenali diri sendiri bangun yang memiliki potensi dalam dirinya (Among dan grace, 2017: 3).

Penyelenggaraan pendidikan di Indonesia melalui tiga jalur, yaitu pendidikan formal, pendidikan non formal dan pendidikan informal. Pendidikan formal merupakan jalur pendidikan yang diselenggarakan di sekolah yang berjenjang dan berkelanjutan. Pendidikan non formal merupakan jalur pendidikan yang diselenggarakan oleh masyarakat yang tidak terlalu sistematis dan terencana, sedangkan pendidikan informal merupakan jalur pendidikan yang dilakukan seseorang dari pengalaman sehari-hari dengan sadar maupun tidak sadar dari seseorang lahir hingga meninggal dunia. Pendidikan yang dilakukan di sekolah.

Menurut Jerome S. Bruner dalam Muhibbin Syah (1999:109) siswa menempuh 3 tahap dalam proses belajar yaitu (1). Tahap Informasi (tahap penerimaan materi) (2). Tahap Transformasi (Tahap pengubahan materi) (3). Tahap Evaluasi (Tahap penilaian ). Hambatan-hambatan yang dihadapi siswa dalam proses belajar mengajar dikelas disebut sebagai kesulitan belajar siswa dalam mempelajari konsep Bahasa Inggris yang akan dipelajari oleh siswa VIII ada tiga konsep, yaitu Reading, Structure, dan Listening. Konsep-konsep tersebut harus dipelajari dalam waktu 2 semester, tetapi kenyataan di lapangan menunjukkan bahwa konsep tersebut tidak dipelajari secara

ScienceEdu Vol. II. No. 1 June 2019 
mendalam sehingga menyebabkan siswa kesulitan dalam mempelajarinya. Kesulitan belajar pada peserta didik dapat terjadi pada siswa yang berkatagori "di luar rata-rata" (sangat pintar dan sangat bodoh) yang dipengaruhi oleh tingkat kecerdasan, pengetahuan, bakat, kepribadian, sikap, kebiasaan, sifat dan latar.

Sedangkan dalam penelitian Catherine McBride (2011) yang berjudul "Model pelayanan berkesulitan belajar pada umumnya dan anak berkesulitan belajar pada khususnya" menunjukkan bahwa Pelayanan anak berkesulitan belajar ditinjau dari program penempatan terdapat tiga model yaitu kelas regular, kelas khusus dan sekolah khusus. Pelayanan anak ditinjau dari jenis guru yang menangani ada model guru sebagai berikut (1) guru kelas (2) guru kunjung (3)guru khusus (4) konsultan dan tutor. Dalam kesempatan penelitian ini dibatasi model pelayanan dengan program penempatan kelas khusus, kelas regular dan kelas konvensional. Dalam model pelayanan ini anak berkesulitan belajar ringan dan anak normal ditempatkan dalam satu kelas, mendapat pelayanan belajar yang sama oleh guru kelas yang telah dilatih sesuai dengan prinsip falsafah normalisasi. Pelayanan kelas regular memberikan kemudahan tumbuhnya kepribadian yang utuh dan penuh baik bagi anak normal maupun anak berkesulitan belajar.

Pelayanan kelas khusus merupakan sistem pelayanan campuran antara system integrasi dan sistem segresi. Anak berkesulitan belajar dilayani bersama anak normal, tetapi pada waktu tertentu dilayani terpisah dengan anak normal. Pelayanan di kelas khusus cocok untuk menangani kasuskasus sulit yang ditangani dalam kelas regular, kondisi lingkungan kelas khusus cocok untuk menangani anak berkesulitan belajar ringan dan berat, kelas khusus dapat menguatkan harga diri dan tanggung jawab, Guru dapat memusatkan perhatiannya secara penuh terhadap kebutuhan anak berkesulitan belajar yang berbeda-beda.

Menurut Abu Ahmad dan Widodo (1991:89-91) upaya untuk mengetahui adanya kemungkinan siswa mengalami kesulitan belajar diadakan penyelidikan antara lain dengan:

1. Observasi, yaitu mengadakan pengamatan secara langsung terhadap objek (siswa).

2. Interview, yaitu melakukan wawancara langsung terhadap siswa yang di selidiki atau terhadap orang lain yang dapat memberikan informasi tentang siswa yang di selidiki.

3. Tes diagnostic, yaitu tes untuk mengetahui siswa yang mengalami kesulitan belajar. Tes ini dapat berupa tes buatan guru (teacher made test).

4. Dokumentasi, yaitu melihat catatan-catatan, arsip-arsip, dokumendokumen yang berhubungan dengan siswa.

\section{METODE PENELITIAN}

Dalam penelitian ini saya menggunakan metode penelitian kualitatif. Menurut Gunawan (2013:80) Menyatakan bahwa dengan pendekatan qualitative menekankan pada proses dari proses berpikir secara induktif yang berkaitan dengan hubungan antar fenomena yang diamati dan senantiasa menggunakan logika ilmiah. Penelitian ini dilakukan dengan cara study literature dan wawancara ke beberapa siswa SMP/MTs DIPONEGORO WULUHAN. penelitian ini berlangsung pada tanggal 2-5 oktober 2018. Adapun Tekhnik pengumpulan data yang digunakan adalah studi literature dan wawancara ke masing-masing siswa berbeda kelas.

\section{HASIL DAN PEMBAHASAN}

Kesulitan belajar (learning difficulty) terjadi karena siswa tidak mendapat kesempatan dalam mempelajari Bahasa Inggris yang bersumber pada :

kosa kata

1) Kesulitan membaca kalimat dan

Kesulitan membaca terutama bila kalimat itu merupakan kalimat pasif, kalimat aktif lebih mudah di mengerti oleh siswa. Pengertian kosa kata menurut para ahli adalah gabungan kata yang dengan cermat mengungkapkan sesuatu makna konsep, keadaan, atau sifat yang khas dalam bidang tertentu. Seringkali siswa tidak memahami benar istilah yang digunakan. Beberapa siswa hanya menghafal saja tanpa 
memahami apa maksud sebenarnya.

2) Kesulitan memahami konsep

Dalam Bahasa Inggris banyak ditemukan konsep, Konsep adalah gagasan mengenai materi yang dapat dinyatakan dengan kata atau istilah. Sedangkan pengertian teori menurut pendapat para ahli adalah asas-asas dan hukum-hukum yang menjadi dasar sesuatu ilmu pengetahuan.

Menurut Mulyono Abdurrahman (1999:11) secara garis besar kesulitan belajar dapat diklasifikasikan kedalam 2 kelompok yaitu: (1). Kesulitan belajar yang berhubungan dengan perkembangan ( developmental learning disabilities ), kesulitan belajar ini mencakup gangguan motorik \& persepsi, kesulitan belajar bahasa \& komunikasi, serta kesulitan belajar dalam penyelesaian perilaku sosial (2). Kesulitan belajar akademik (academic learning disabilities), kesulitan belajar ini menunjuk pada adanya kegagalan pencapaian prestasi akademik yang sesuai dengan kapasitas yang diharapkan.

b. Faktor-Faktor Penyebab

Kesulitan Belajar

Kesulitan belajar tidak hanya dialami oleh siswa dengan kemampuan rendah saja tetapi juga pada siswa berkemampuan ratarata (normal) bahkan siswa dengan kemampuan tinggi. Hal ini disebabkan oleh faktor-faktor tertentu yang menghambat tercapainya kinerja akademik yang sesuai dengan harapan. Menurut Muhibbin Syah (2006:173) faktor-faktor yang menyebabkan kesulitan belajar meliputi :

1. Faktor Intern Siswa

Faktor intern siswa meliputi gangguan atau kekurangmampuan psikofisik siswa, yakni :

a. Yang bersifat kognitif (ranah cipta), antara lain seperti rendahnya kapasitas intelektual / intelegensi siswa.

b. Yang bersifat afektif (ranah rasa), anatara lain seperti labilnya emosi dan sikap.

c. Yang bersifat psikomotor (ranah karsa), antara lain seperti tertanggungnya alat-alat indera penglihatan dan pendengar.

2. Faktor ekstern siswa

Faktor ekstern siswa meliputi semua situasi dan kondisi lingkungan sekitar yang tidak mendukung aktivitas belajar siswa. Faktor ini dapat dibagi menjadi tiga macam, yaitu:

a. Lingkungan Keluarga, contohnya: ketidakharmonisan hubungan antara ayah dengan ibu, dan rendahnya kehidupan ekonomi keluarga.
b.
Lingkungan

Perkampungan/masyarakat, contohnya: wilayah perkampungan kumuh (slum area), dan teman sepermainan yang nakal.

c. Lingkungan Sekolah, contohnya : kondisi dan letak gedung sekolah yang buruk seperti dekat pasar, kondisi guru serta alat-alat belajar yang berkualitas rendah.

\section{DAFTAR PUSTAKA}

Abdurrahman, Mulyono. 2012. Pendidikan Bagi Anak Berkesulitan Belajar. Jakarta: PT. Rineka Cipta.

Among, neolaka dan grace amialia a. Neoloka. 2017. Landasan pendidikan: dasar pengenlan diri sendiri menuju perubahan hidup. Depok: Kencana

Gunawan, I. 2013. Metode Penelitian Kualitatif Teori Dan Praktik. Jakarta:Bumi Aksara

Kartakusumah, berliana. 2006. Pemimpin adiluhung: genealogi kepemimpinan kontenporer. Jakarta selatan: teraju.

Nofrion. 2016. Komunikasi pendidikan: penerapan teori dan konsep komunikasi dalam pembelajaran. Jakarta: kencana.

Raharjo, tri joko dan tri suminar. Penerapan Pedagogi Dan Andragogi Pada Pembelajaran Pendidikan Kesetaraan Kelompok Belajar Paket A, B, Dan C Di Kota Semarang. Vol. 1 No. 1,edukasi semarang 2016. .

Slameto. 2003. Belajar dan Faktor-Faktor yang Mempengaruhinya. Jakarta: Rineka Cipta.

Tilaar, h.a.r. 2003. Kekuasaan \& pendidikan: suatu tinjauan dari 
prespektif studi kultural. Magelang:

Indonesia Tera 